\title{
Synthesis, characterization and electrocatalytic properties of Delafossite $\mathrm{CuGaO}_{2}$
}

Jahangeer Ahmed ${ }^{\mathrm{a}, \mathrm{b}}$ and Yuanbing $\mathrm{Mao}^{\mathrm{a}}{ }^{\mathrm{t}}$

${ }^{a}$ Department of Chemistry, University of Texas Rio Grande Valley, 1201 West University Drive, Edinburg, TX 78539, United States.

${ }^{\mathrm{b}}$ Current address: Department of Chemistry, College of Science, King Saud University, Riyadh 11451, Saudi Arabia

${ }^{\dagger}$ To whom correspondence should be addressed: Phone: +1 956665 2417; Fax: +1 956665

5006; E-mail: yuanbing.mao@utrgv.edu.

\begin{abstract}
Delafossite $\mathrm{CuGaO}_{2}$ has been employed as photocatalysts for solar cells, but their electrocatalytic properties have not been extensively studied, especially no comparison among samples made by different synthesis routes. Herein, we first reported the successful synthesis of delafossite $\mathrm{CuGaO}_{2}$ particles with three different morphologies, i.e. nanocrystalline hexagons, sub-micron sized plates and micron-sized particles by a modified hydrothermal method at $190^{\circ} \mathrm{C}$ for $60 \mathrm{~h},{ }^{1,2,3}$ a sono-chemical method followed by firing at $850^{\circ} \mathrm{C}$ for $48 \mathrm{~h}$, and a solid state route at $1150^{\circ} \mathrm{C}$, respectively. Morphology, composition and phase purity of the synthesized samples was confirmed by powder X-ray diffraction and Raman spectroscopic studies, and then their electrocatalytic performance as active and cost effective electrode materials to the oxygen and hydrogen evolution reactions in $0.5 \mathrm{M} \mathrm{KOH}$ electrolyte versus $\mathrm{Ag} / \mathrm{AgCl}$ was investigated and compared under the same conditions for the first time. The nanocrystalline $\mathrm{CuGaO}_{2}$ hexagons show enhanced electrocatalytic activity than the counterpart sub-micron sized plates and micronsized particles.
\end{abstract}

\section{Keywords:}

$\mathrm{CuGaO}_{2}$; Delafossite; Oxygen evolution reaction; Hydrogen evolution reactions; Electrocatalytic activity 


\section{Graphical abstract}
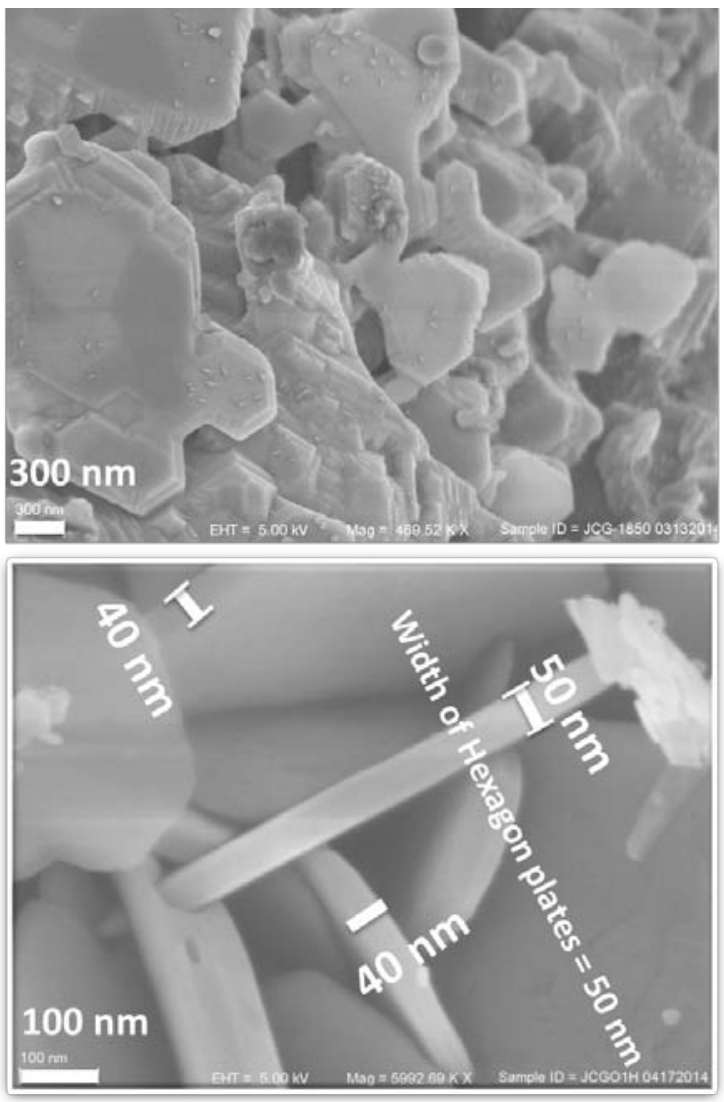
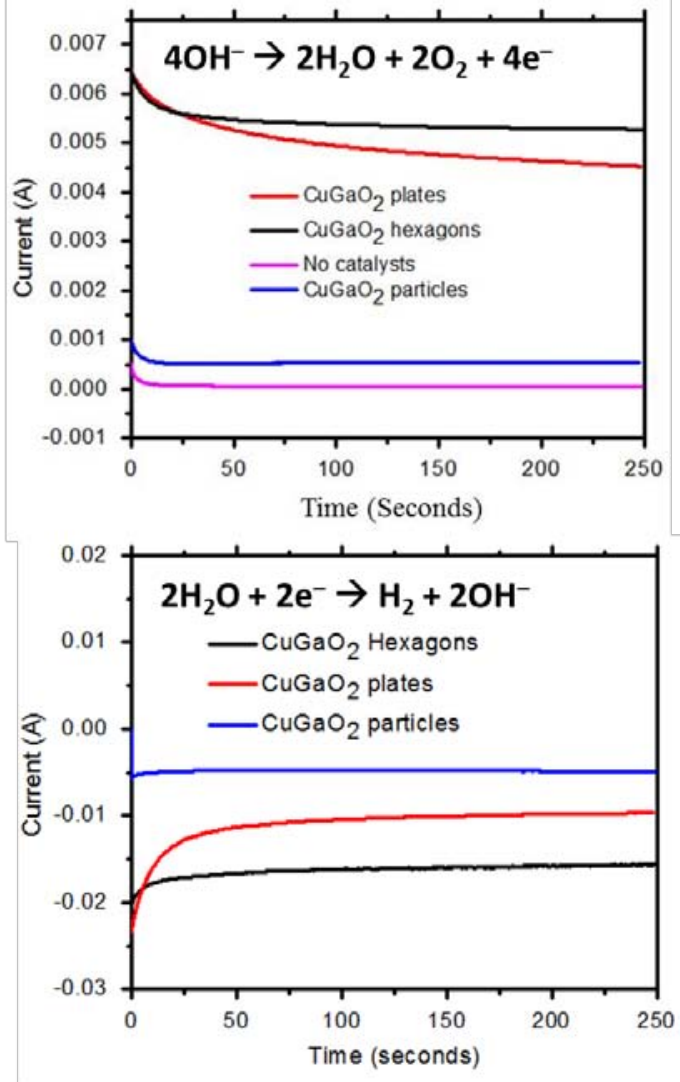


\section{Introduction}

Delafossite ternary oxides have an $\mathrm{AMO}_{2}$-type general structure, where ' $\mathrm{A}$ ' is monovalent (1+ metals like $\mathrm{Cu}, \mathrm{Ag}$, etc.) and ' $\mathrm{M}$ ' is trivalent (3+ metals like $\mathrm{Al}, \mathrm{Ga}$, In, Fe etc.). Delafossite $\mathrm{CuMO}_{2}$ with monovalent $\mathrm{Cu}$ ion has closed packed plane with edge sharing of $\mathrm{MO}_{6}$ octahedra., It belongs to a group of $p$-type transparent conducting oxides and has a band gap of $3.6 \mathrm{eV}$. $^{6,7}$ The $p$-type conductivity in delafossite compounds was first discovered by Kawazoe et al in $1997 .{ }^{8}$ The conductivity and electronic structures of delafossite $\left(\mathrm{CuM}^{\mathrm{III}} \mathrm{O}_{2}\right)$ materials are reported in details elsewhere. ${ }^{1,9}$ Delafossite $\mathrm{CuGaO}_{2}$ demonstrates very interesting properties including optical, ${ }^{9,10}$ electronic, ${ }^{7,9,10}$ and photovoltaic properties. ${ }^{2,3,11} \mathrm{CuGaO}_{2}$ nanoplates have been used as the photo-electrode materials in p-type dye sensitized solar cells to accelerate the photo-voltage and photocurrent. ${ }^{2,3}$ Sub-micron sized $\mathrm{CuGaO}_{2}$ particles were also used as photo-electrode materials in the $\mathrm{H}_{2}$ generation by splitting of hydrogen sulfide ${ }^{12}$ and photochemical reduction of $\mathrm{CO}_{2}$ to $\mathrm{CO}{ }^{13}$ Electrochemical impedance spectroscopy was employed to determine the hole conductivity and acceptor density of $\mathrm{CuGaO}_{2}$ nanoparticles. ${ }^{14}$ Other than studies on $\mathrm{CuGaO}_{2}$, as the literature review points out, there were very few reports on the electro-catalysis of delafossite materials, e.g. $\mathrm{PtCoO}_{2},{ }^{15} \mathrm{PdCoO}_{2},{ }^{15} \mathrm{PdRhO}_{2},{ }^{15} \mathrm{CuRhO}_{2},{ }^{16,17} \mathrm{CuAlO}_{2},{ }^{17,18}$ but not extensively, nor comparatively among different morphologies. Hinogami et al have reported $\mathrm{CuRhO}_{2}$ delafossite as active electrocatalysts for oxygen evolution reaction (OER) using $1.0 \mathrm{M} \mathrm{KOH}$ electrolyte and reversible hydrogen electrode as a reference electrode. ${ }^{17}$ Copper based nanostructures including oxides $^{19}$ and intermetallic ${ }^{20,21}$ have also been used as the electrocatalysts in hydrogen evolution reaction (HER) and OER using 0.5 M KOH electrolyte versus $\mathrm{Ag} / \mathrm{AgCl}$ as a reference electrode. Therefore, delafossites with copper at the A-site have demonstrated significant electronic properties but their electrochemical studies are still lacking, ${ }^{8,14}$ which motivates us to study delafossite $\mathrm{CuGaO}_{2}$ with different morphologies on their electrochemical performance to OER and HER.

Delafossite $\mathrm{CuGaO}_{2}$ nanostructures are of great interest in electrolysis of water for oxygen and hydrogen evolutions. Renewable and clean energy is the most important challenge for scientists due to the declining non-renewable energy sources (i.e. coal and oil). Hydrogen is an important form of energy carrier for next generation fuel to run the world's economy and has higher energy content. Electrolysis of water for hydrogen and oxygen evolution has an immense potential to supply sustainable energy via fuel cells, battery devices etc. Hydrogen is also a clean fuel which 
can be used in the fuel cells by converting the chemical energy in to electrical energy. Hydrogen also combines with oxygen to produce electricity in a fuel cell. Oxygen could also be used in fuel cells in the generation of power by increasing the temperature of the reactor to complete the combustion of fuels. More specifically, the aim of the present work is to provide active and cost effective delafossite $\mathrm{CuGaO}_{2}$ electro-catalysts for OER and HER. Oxygen and hydrogen are commonly used as fuels in power generations, automobile and aerospace industries. Here, we report that nanocrystalline $\mathrm{CuGaO}_{2}$ hexagons show enhanced electro-catalytic activity as compared to the sub-micron sized and micron sized particles of $\mathrm{CuGaO}_{2}$ counterparts for the OER and HER in $0.5 \mathrm{M} \mathrm{KOH}$ versus $\mathrm{Ag} / \mathrm{AgCl}$. The structural and morphological characterizations of the materials were investigated by powder x-ray diffraction (PXRD), Raman spectroscopy, thermo-gravimetric analysis, energy dispersive studies and electron microscopic studies. The electrochemical studies were successfully carried out using three electrode based electrochemical work station. The electrolysis of water by using the synthesized delafossite $\mathrm{CuGaO}_{2}$ catalysts shows a clear feasibility of current generation in alkaline electrolyte. Besides, these delafossite $\mathrm{CuGaO}_{2}$ materials could be useful to sustain the energy through fuel cells, battery devices, electrolyzer, solar water splitting, etc.

\section{Experimental Section}

\section{Materials and methods:}

The following reagents were used in the synthesis of $\mathrm{CuGaO}_{2}$ delafossites: $\mathrm{Cu}\left(\mathrm{NO}_{3}\right)_{2} \cdot 3 \mathrm{H}_{2} \mathrm{O}$ (Sigma Aldrich, 99\%), $\mathrm{Ga}\left(\mathrm{NO}_{3}\right)_{3} \bullet \mathrm{xH}_{2} \mathrm{O}$ (Alfa Aesar, 99.9\%), PEG 20,000 (Polyethylene glycol) (Alfa Aesar), ethylene glycol (Alfa Aesar, 99\%), $\mathrm{KOH}$ (JT Baker Chemical Company), $\mathrm{NaHCO}_{3}$ (Sigma Aldrich, 99.7\%), and ethanol (Alfa Aesar, 96\%). Thermal analysis of the commercial $\mathrm{Ga}\left(\mathrm{NO}_{3}\right)_{3} \cdot \mathrm{xH}_{2} \mathrm{O}$ produces a mass loss of $\sim 74 \%$, which corresponds to loss of six water molecules as reported. ${ }^{22}$ Therefore, we have used six water molecules of $\mathrm{Ga}\left(\mathrm{NO}_{3}\right)_{3} \bullet \mathrm{xH}_{2} \mathrm{O}$ in our experiments to maintain the stoichiometric ratio of 1:1 of $\mathrm{Cu}: \mathrm{Ga}$.

\section{Hydrothermal synthesis of nanocrystalline $\mathrm{CuGaO}_{2}$ hexagons:}

Nanocrystalline delafossites $\mathrm{CuGaO}_{2}$ hexagons were synthesized using the modified hydrothermal method. ${ }^{1,2,3}$ An appropriate stoichiometric mixture of copper and gallium precursors in the molar ratio of 1:1, i.e. 0.002 mole of $\mathrm{Cu}\left(\mathrm{NO}_{3}\right)_{2} \cdot 2.5 \mathrm{H}_{2} \mathrm{O}$ and 0.002 mole of $\mathrm{Ga}\left(\mathrm{NO}_{3}\right)_{3} \cdot 6 \mathrm{H}_{2} \mathrm{O}$, was added into a $100 \mathrm{ml}$ Teflon vessel. Subsequently, $10 \mathrm{ml}$ of deionized 
water, $10 \mathrm{ml}$ of absolute ethanol, $5 \mathrm{ml}$ of ethylene glycol and $100 \mathrm{mg}$ of PEG 20,000 were added into the vessel. Then $15 \mathrm{ml}$ of $0.5 \mathrm{M} \mathrm{KOH}$ solution was added to the autoclave containing the resulting mixture $(\mathrm{pH} \sim 8)$ and kept at $190^{\circ} \mathrm{C}$ for $60 \mathrm{~h}$. A mixture of ethanol and water has been used as a solvent in the hydrothermal process. The surface tension of ethanol $(22.39 \mathrm{mN} / \mathrm{m})$ is lower than water $(77.82 \mathrm{mN} / \mathrm{m})$ at room temperature. High surface tension of the solvent would lead agglomeration of the particles. Addition of ethanol in water decreases the surface tension of the solvent that could help to increase the reaction kinetics of $\mathrm{CuGaO}_{2}$ particles and decrease the agglomeration of the particles. The resulting products were washed with ammonia and dilute nitric acid followed by washing with deionized water. Finally a light yellow colored powder was collected and dried at $70^{\circ} \mathrm{C}$ for $4 \mathrm{~h}$.

\section{Sono-chemical synthesis of sub-micron sized $\mathrm{CuGaO}_{2}$ plates:}

The sono-chemical synthesis involved the mixing of parent materials $\left(0.03 \mathrm{M} \mathrm{Cu}\left(\mathrm{NO}_{3}\right)_{2} \cdot 3 \mathrm{H}_{2} \mathrm{O}\right.$ and $\left.0.03 \mathrm{M} \mathrm{Ga}\left(\mathrm{NO}_{3}\right)_{3} \cdot \mathrm{xH}_{2} \mathrm{O}\right)$ followed by titration with $0.15 \mathrm{M} \mathrm{NaHCO}_{3}$ solutions drop by drop at $25^{\circ} \mathrm{C}$ under ultrasonic process and kept for $3 \mathrm{~h}$. The light green precipitates were collected by centrifugation and washed with deionized water three times. The resulting products were then dried at $60^{\circ} \mathrm{C}$ for $6 \mathrm{~h}$ and used as the precursor materials in the synthesis of the delafossite $\mathrm{CuGaO}_{2}$ sub-micron sized plates by annealing the above precursor at $850^{\circ} \mathrm{C}$ for $48 \mathrm{~h}$ under ultrapure nitrogen (99.999\%) flow to form grey colored $\mathrm{CuGaO}_{2}$ plates.

\section{Solid state route of synthesis of micron-sized $\mathrm{CuGaO}_{2}$ particles:}

Micron-sized $\mathrm{CuGaO}_{2}$ particles were synthesized via solid state route. Gallium oxide $\left(\mathrm{Ga}_{2} \mathrm{O}_{3}\right.$, Sigma Aldrich, 98\%) and copper oxide nanopowder (CuO, Sigma Aldrich, size 50 nm) were taken in 1:2 molar ratio and ground together in an agate mortar pestle for 30 minutes. The resulting precursor was then annealed at $1150^{\circ} \mathrm{C}$ for $36 \mathrm{~h}$ under $\mathrm{N}_{2}$ gas flow.

\section{Characterizations:}

All the resulting products were initially characterized by PXRD to determine the phase purity of the obtained delafossite $\mathrm{CuGaO}_{2}$ samples using a Bruker D8 Advanced diffractometer with Nifiltered $\mathrm{Cu}-K_{\alpha}$ radiation at a scan speed of 1 second and scan step of 0.02 degree on a zero background sample holder. Raman scattering data was collected on a Bruker SENTERRA RAMAN microscope with an objective of 20X of optical microscope. The excitation line (785 $\mathrm{nm}$ ) of an $\mathrm{Ar}^{+}$laser beam was focused to a spot size of $5 \mu \mathrm{m}$ with a laser power of $10 \mathrm{~mW}$. The 
spectral resolution range was used $3-5 \mathrm{~cm}^{-1}$ with the integration time of $100 \mathrm{~s}$. Electron microscopic studies were carried out with a ZEISS SIGMA VP field emission scanning electron microscope (FESEM) operated at $5 \mathrm{kV}$. Transmission electron microscopic (TEM) studies were carried out with a ZEISS LEO 900 electron microscope operated at $80 \mathrm{kV}$. TEM specimens for the measurements were prepared by dispersing the delafossite $\mathrm{CuGaO}_{2}$ powder samples in ethanol via ultra-sonication, a drop was put onto a porous carbon film supported by a copper grid, and then dried in air. Thermo-gravimetric analysis (TGA) was carried out using a PerkinElmer system with a heating rate of $5^{\circ} \mathrm{C} / \mathrm{min}$ in oxygen atmosphere.

\section{Preparation of electrode materials and electrochemical measurements:}

The electrochemical studies were carried out with a computer controlled potentiostat/galvanostat electrochemical work station (Metrohm Autolab B.V.) at room temperature. Three electrodes (Pt wire, $\mathrm{Ag} / \mathrm{AgCl}$, and glassy carbon electrodes as the counter electrode, reference electrode and working electrode, respectively) were used in the electrolysis of water to OER and HER. The working electrodes were prepared by pasting slurries of the $\mathrm{CuGaO}_{2}$ powders mixed with carbon black and PVDF (weight fractions of $\mathrm{CuGaO}_{2}$ :carbon black:PVDF of 75:15:10) on the surface of glassy carbon electrode. PVDF (polyvinylidene difluoride) was used as a binder with carbon black as conductive additive in the preparation of electrode materials. The prepared electrodes were then dried at $65^{\circ} \mathrm{C}$ for overnight in vacuum oven and used as a working electrode for the electrochemical measurements. Cyclic voltammetry (CV) was carried at the scan rate of $50 \mathrm{mV} / \mathrm{s}$ with a peak window between from -1.0 to $1.1 \mathrm{~V}$ versus $\mathrm{Ag} / \mathrm{AgCl}$ electrode in $0.5 \mathrm{M} \mathrm{KOH}$ electrolyte. Electrolyte solution of $0.5 \mathrm{M} \mathrm{KOH}(a q)$ versus $\mathrm{Ag} / \mathrm{AgCl}$ electrode (reference electrode) has been used in present electrochemical studies according to the literature. . $^{8,19,20,21}$ Chronoamperometric measurements were carried out for $200 \mathrm{~s}$ at $0.60 \mathrm{~V}$ and $-1.2 \mathrm{~V}$ versus $\mathrm{Ag} / \mathrm{AgCl}$ for OER and HER, respectively, in $0.5 \mathrm{M} \mathrm{KOH}$ electrolyte. Carbon corrosion at a high potential is largely responsible to ruin the OER performances. Therefore, to avoid the carbon corrosion, we have studied the oxygen evolution reactions (OER) at low potential $(0.60 \mathrm{~V})$ using chronoamperometry. Nitrogen gas was purged through the electrolyte for 5 minutes prior to the electrochemical measurements to remove dissolved air from the electrolyte toward the OER and HER. Also electrochemical measurements were run in $\mathrm{O}_{2}$-saturated $0.5 \mathrm{M} \mathrm{KOH}$ for OER. Note that freshly prepared electrodes and electrolytes were used in each measurement for the OER and 
HER studies. The current density of the $\mathrm{CuGaO}_{2}$ electro-catalysts was calculated using the surface area, amount of catalysts pasted on the glassy carbon and generated current.

\section{Results and discussion}

Using the sono-chemical method, crystalline sub-micron sized $\mathrm{CuGaO}_{2}$ plates were synthesized after annealing the precursor materials prepared at $25^{\circ} \mathrm{C}$ in $\mathrm{N}_{2}$ atmosphere at $850^{\circ} \mathrm{C}$. Figure 1a shows the PXRD pattern of the green colored precursors obtained from the sono-chemical method showing the crystalline phases of basic copper carbonate $\left(\mathrm{Cu}_{2}(\mathrm{OH})_{2} \mathrm{CO}_{3}\right)$ and gallium hydroxide $\left(\mathrm{Ga}(\mathrm{OH})_{3}\right)$. This green colored precursor was converted into grey colored $\mathrm{CuGaO}_{2}$ powder with rhombohedral crystal structure (Figure 1b) after fired at $850^{\circ} \mathrm{C}$ for $48 \mathrm{~h}$ under $\mathrm{N}_{2}$ gas flow. As reported in the literature, $\mathrm{CuGaO}_{2}$ is thermodynamically unstable at or below

$1100^{\circ} \mathrm{C}$ and $1200^{\circ} \mathrm{C}$ in nitrogen and air, respectively. ${ }^{23,24}$ Phase pure nanocrystalline $\mathrm{CuGaO}_{2}$ hexagons in light yellow color were synthesized using the modified hydrothermal methods at $190^{\circ} \mathrm{C}$ (Figure 1c). All the observed reflections from the PXRD studies could be indexed with the peaks of (003), (006), (101), (012), (104), (015) and (018) on the basis of rhombohedral unit cell with the space group R-3m (JCPDS file \# 00-035-1402). Figure $1 \mathrm{~d}$ shows the pure phase of micron-sized $\mathrm{CuGaO}_{2}$ particles obtained at $1150^{\circ} \mathrm{C}$ for $36 \mathrm{~h}$ in $\mathrm{N}_{2}$ via the solid state route. Figure 1d shows narrower XRD pattern of the $\mathrm{CuGaO}_{2}$ particles obtained at $1150^{\circ} \mathrm{C}$ via solid state route as compared to the other two $\mathrm{CuGaO}_{2}$ samples (Figures 1d vs 1c $\& 1 \mathrm{~b}$ ). This could be possible because the crystalline size of the three $\mathrm{CuGaO}_{2}$ samples increases with processing temperatures. The temperature of the synthesis reaction, the nature of the reactants and the way of the preparation of materials play crucial roles in the formation of materials. Therefore, Bragg's reflections of the (hkl) depend on the crystallinity and size of the obtained samples. 

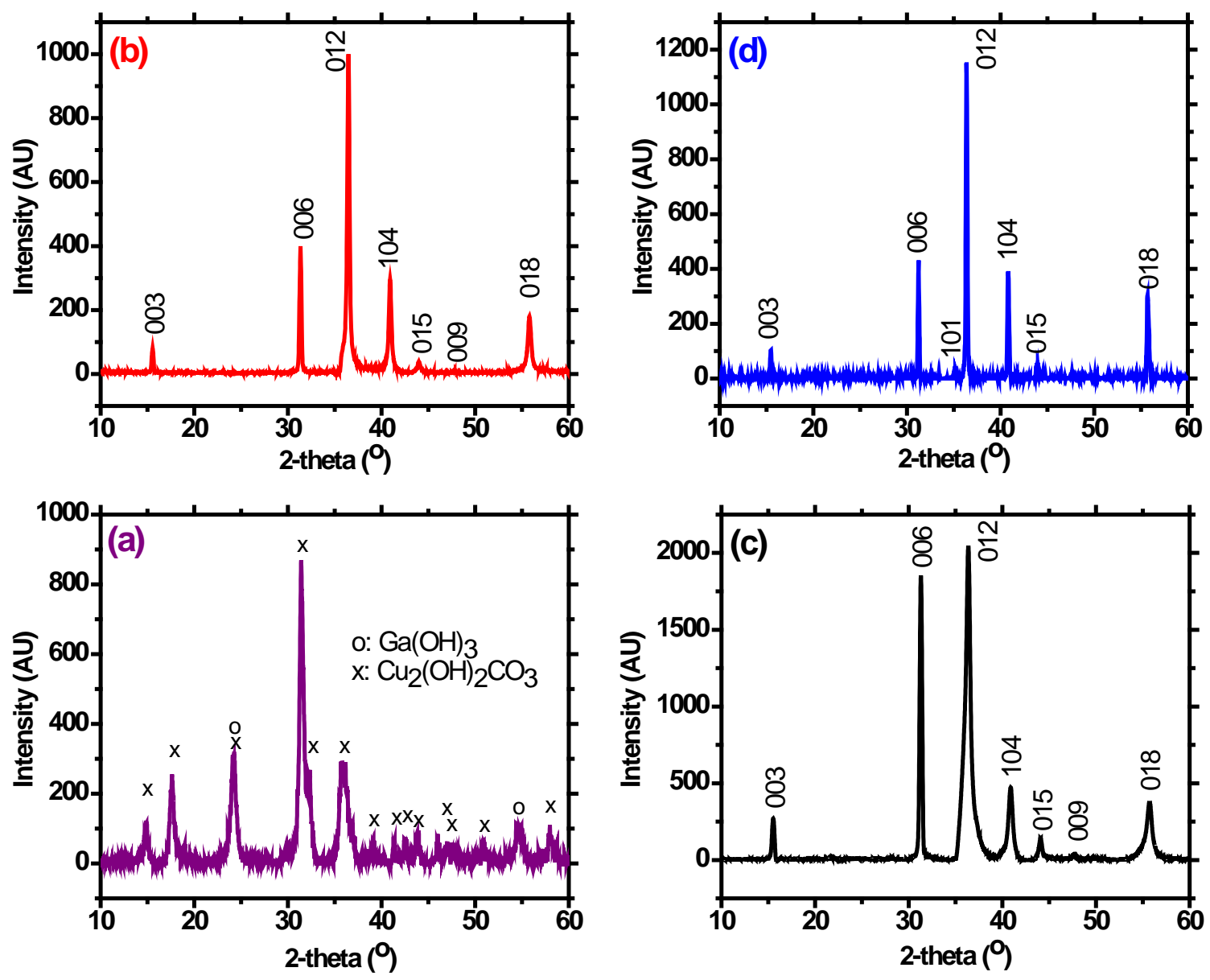

Figure 1. PXRD patterns of (a) the as-synthesized precursor by the sono-chemical method; (b) the sub-micron sized $\mathrm{CuGaO}_{2}$ plates obtained by firing the sono-chemical precursor at $850^{\circ} \mathrm{C}$ for $48 \mathrm{~h}$ in $\mathrm{N}_{2}$; (c) the nanocrystalline $\mathrm{CuGaO}_{2}$ hexagons obtained by the hydrothermal method at $190^{\circ} \mathrm{C}$ for $60 \mathrm{~h}$; (d) the micron-sized $\mathrm{CuGaO}_{2}$ particles obtained by solid state route at $1150^{\circ} \mathrm{C}$ for $36 \mathrm{~h}$ in $\mathrm{N}_{2}$.

Moreover, Raman spectra of these nanocystalline hexagons, sub-micron sized plates and micronsized particles of $\mathrm{CuGaO}_{2}$ were collected by employing normal backscattering geometry as shown in Figure 2. For the sub-micron sized $\mathrm{CuGaO}_{2}$ plate sample, three characteristic Raman bands are identified at 203, 362 and $730 \mathrm{~cm}^{-1}$, assigned to the $A_{\mathrm{g}}, E_{\mathrm{g}}$, and $A_{1 \mathrm{~g}}$ modes of rhombohedral structure, respectively, which agree well with that of the reported delafossite $\mathrm{CuGaO}_{2} \cdot{ }^{25,26}$ All these three Raman bands of $A_{\mathrm{g}}, E_{\mathrm{g}}$, and $A_{1 \mathrm{~g}}$ also appear with nanocrystalline 
$\mathrm{CuGaO}_{2}$ hexagons and micron-sized particles at 204, 367 and $737 \mathrm{~cm}^{-1}$, respectively. The $A_{\mathrm{g}}$ and $A_{1 \mathrm{~g}}$ phonon modes denote the atomic vibrations in the direction of c-axis along the $\mathrm{O}-\mathrm{Cu}-\mathrm{O}$ bonds while the $E_{\mathrm{g}}$ mode (double degenerate) describes the vibration in the perpendicular direction along the c-axis. A small shift in the Raman peak positions of $\mathrm{E}_{\mathrm{g}}$ and $A_{1 \mathrm{~g}}$ phonon modes to the higher wavenumbers was observed when comparing the nanocrystalline $\mathrm{CuGaO}_{2}$ hexagons and micron-sized particles with the sub-micron sized $\mathrm{CuGaO}_{2}$ plates. This small shift in the $E_{\mathrm{g}}$ and $A_{1 \mathrm{~g}}$ phonon modes (Raman active mode) could be due to the surface effects or disorder in the powder with pressure. ${ }^{26}$

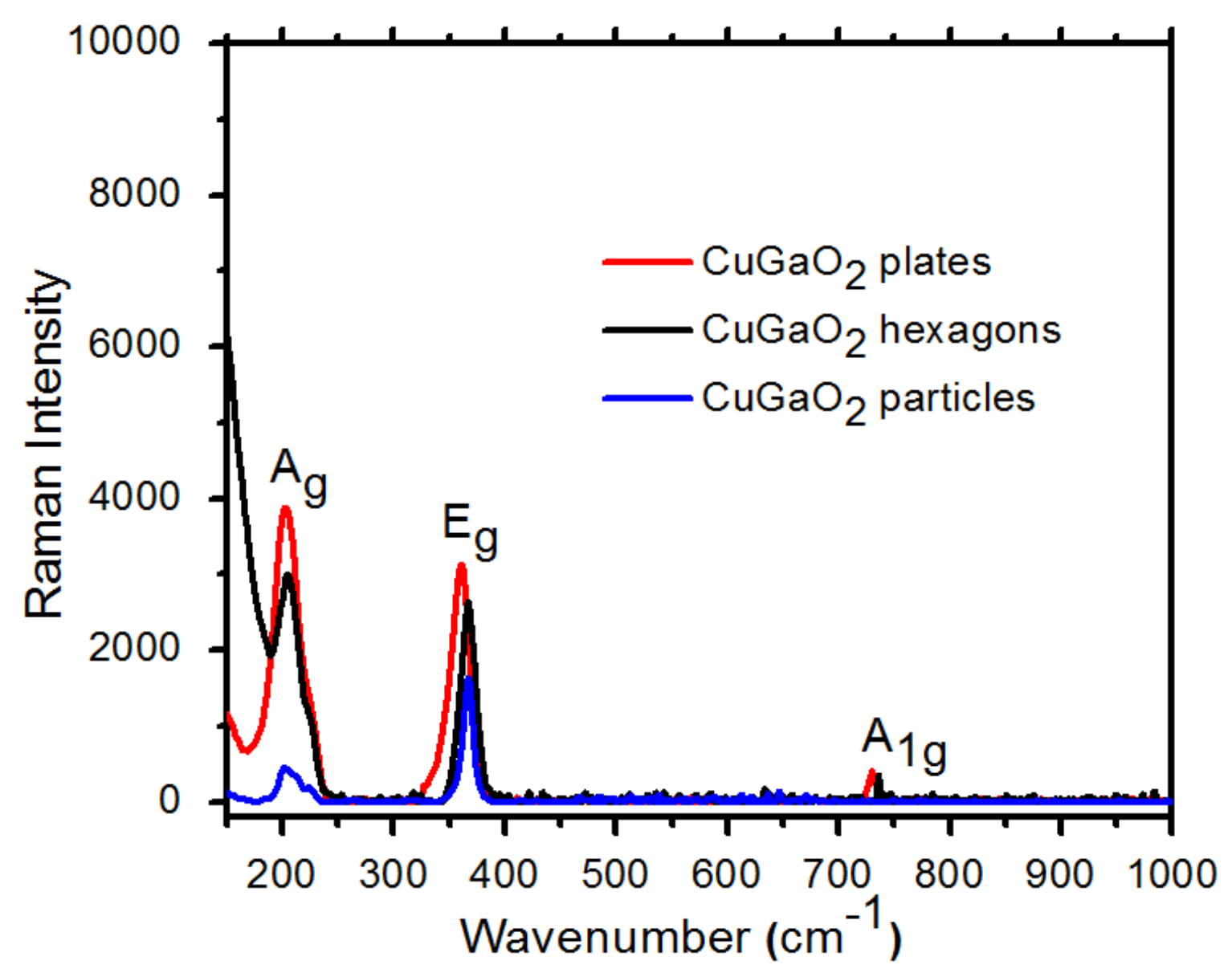

Figure 2. Raman spectra of the nanocrystalline $\mathrm{CuGaO}_{2}$ hexagons, sub-micron sized $\mathrm{CuGaO}_{2}$ plates, and micron-sized $\mathrm{CuGaO}_{2}$ particles.

The microscopic studies by FESEM show the formation of plate-like morphology of $\mathrm{CuGaO}_{2}$ particles from the sono-chemical method followed by firing at $850^{\circ} \mathrm{C}$ with some agglomerations 
(Figure 3a). The average size of the sub-micron sized plates was found to be in the range from 500 to $800 \mathrm{~nm}$. Figure 3b and 3c show the FESEM images of the hydrothermally synthesized nanocrystalline $\mathrm{CuGaO}_{2}$ hexagons. The low and high magnification FESEM images reveal that the hydrothermally synthesized nanocrystalline $\mathrm{CuGaO}_{2}$ particles have regular hexagonal shape with the average thickness of $\sim 40 \mathrm{~nm}$. TEM studies also show the formation of the polygons with six edges and six verticals with diameter of $\sim 500 \mathrm{~nm}$ (Figure 3d). With more careful visualization by TEM studies, these nanocrystalline $\mathrm{CuGaO}_{2}$ hexagons appear to be composed of tiny nanoparticles with the average particle size of $\sim 10 \mathrm{~nm}$. Similar type of nanoparticle aggregations to sub-micron sized hexagonal plates from other materials have also been reported by micro-emulsion method. ${ }^{27}$ Figure 3e shows the formation of micron-sized spherical shaped particles of $\mathrm{CuGaO}_{2}$ by the solid state method. Energy-dispersive X-ray spectroscopic (EDS) studies confirmed that these delafossite $\mathrm{CuGaO}_{2}$ samples contained only copper, gallium and oxygen elements without any impurity which clearly support the PXRD patterns of these delafossite $\mathrm{CuGaO}_{2}$ samples (Figures $3 f$ \& 1). The elemental composition of the copper and gallium was found according to the initial 1:1 loading stoichiometry. The appearance of carbon content in the EDS studies is mainly due to the surface of carbon tape on sample holder (Figures 3f). From the BET surface area measurements, the specific surface area of the nanocrystalline $\mathrm{CuGaO}_{2}$ hexagons, sub-micron sized $\mathrm{CuGaO}_{2}$ plates and micron-sized $\mathrm{CuGaO}_{2}$ particles were found to be 2.63, 2.33 and $0.42 \mathrm{~m}^{2} / \mathrm{g}$, respectively. So the specific surface area per unit volume of $\mathrm{CuGaO}_{2}$ particles decreases with increasing of particle size of $\mathrm{CuGaO}_{2}$ as expected. 

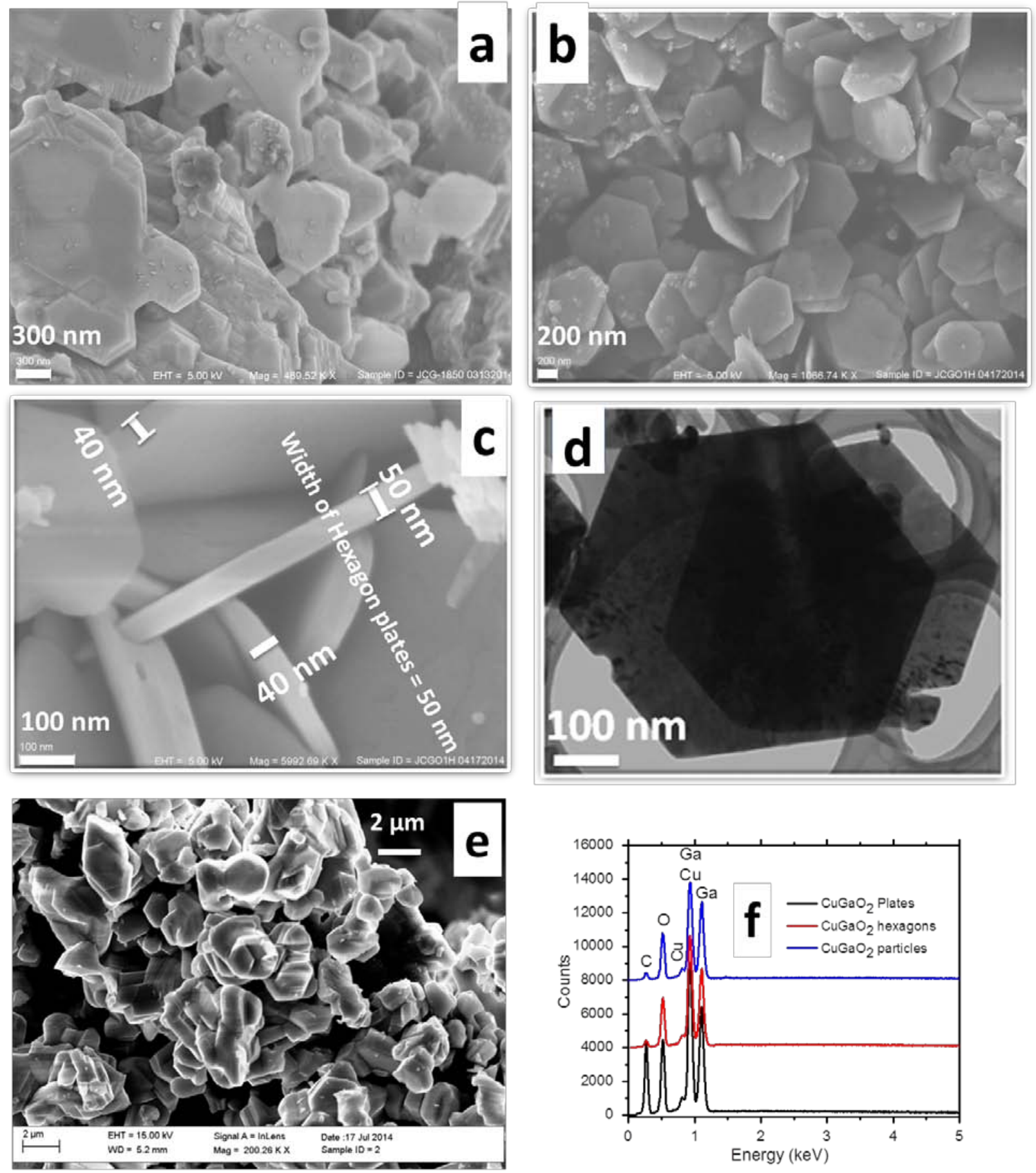

Figure 3. (a) FESEM image of the sub-micron sized $\mathrm{CuGaO}_{2}$ plates; (b) Low- and (c) highmagnification FESEM; (d) TEM images of the nanocrystalline $\mathrm{CuGaO}_{2}$ hexagons; (e) FESEM image of the micron-sized $\mathrm{CuGaO}_{2}$ particles; (f) EDS spectra of the nanocrystalline $\mathrm{CuGaO}_{2}$ hexagons, sub-micron sized $\mathrm{CuGaO}_{2}$ plates and micron-sized $\mathrm{CuGaO}_{2}$ particles. 
Thermal properties of all three delafossite $\mathrm{CuGaO}_{2}$ samples, i.e. sub-micron sized plates, nanocrystalline hexagons and micro-sized particles, were investigated in oxygen atmosphere with the heating rate of $5^{\circ} \mathrm{C} / \mathrm{min}$ up to $800^{\circ} \mathrm{C}$ using the Perkin-Elmer TGA analyzer. As shown in Figure 4, a very small weight loss was initially observed that could be due to the adsorbed moisture, and then the thermal studies of the delafossite $\mathrm{CuGaO}_{2}$ samples showed no weight loss/gain up to $350^{\circ} \mathrm{C}$ in oxygen, which indicates the existence/absence of oxygen deficiency in the $\mathrm{CuGaO}_{2}$ samples. The weight increase above $350^{\circ} \mathrm{C}$ was attributed the decomposition of the $\mathrm{CuGaO}_{2}$ sample. The weight gain was saturated to $\sim 4.9 \%$ at $700^{\circ} \mathrm{C}$, which indicated that the decomposition of $\mathrm{CuGaO}_{2}$ was completed to $\mathrm{CuO}$ and $\mathrm{CuGa}_{2} \mathrm{O}_{4}$ as also reported in the literature. $^{23,24}$

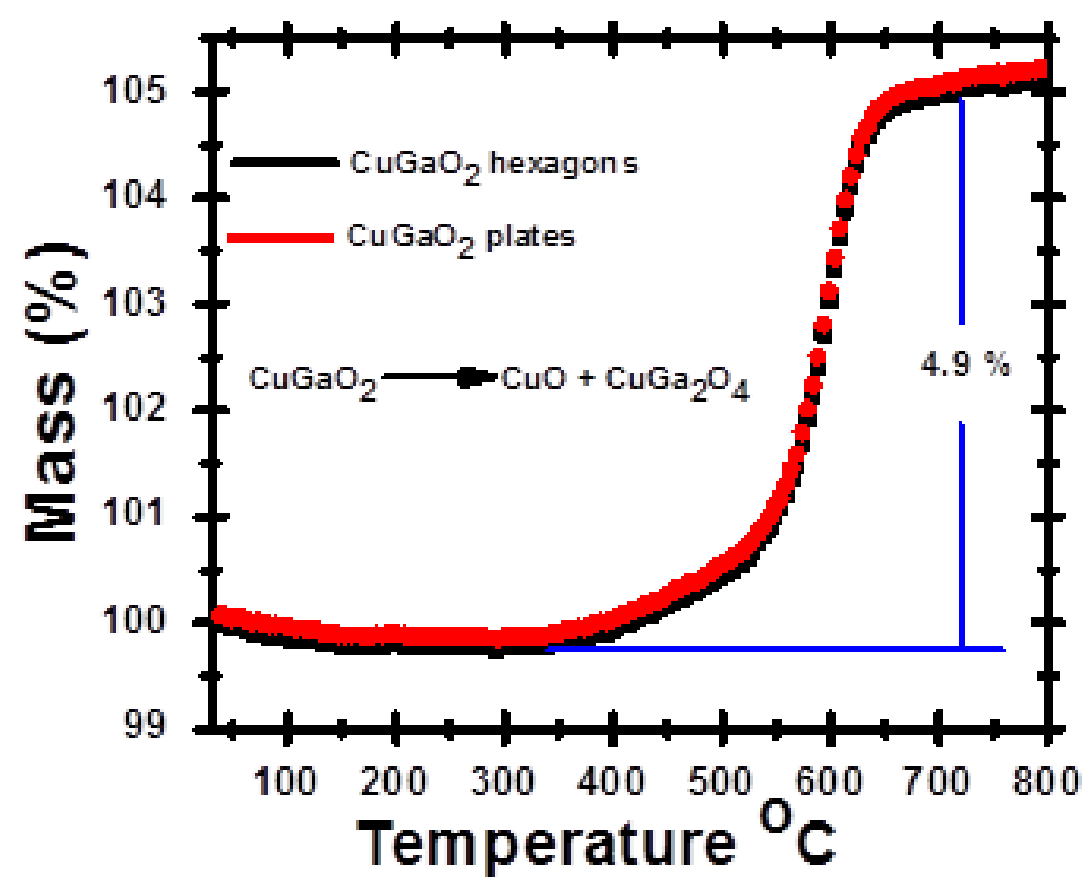

Figure 4. TGA studies of the delafossite $\mathrm{CuGaO}_{2}$ samples (nanocrystalline hexagons and submicron sized plates) in oxygen.

Cyclic voltammetry (CV) and chrono-amperometric (CA) measurements were carried out to test the OER and HER performance of these delafossite $\mathrm{CuGaO}_{2}$ samples with different morphologies. For the electro-catalytic measurements, $0.5 \mathrm{M} \mathrm{KOH}$ and $\mathrm{Ag} / \mathrm{AgCl}$ were used as the electrolyte and reference electrode, respectively, and $\mathrm{N}_{2}$ gas was passed through the electrolyte for 5 min before the tests. Figure 5a shows the CV curves of the nanocrystalline 
hexagons, sub-micron sized plates and micron-sized particles of delafossite $\mathrm{CuGaO}_{2}$ from -1.0 to $1.1 \mathrm{~V}$ versus $\mathrm{Ag} / \mathrm{AgCl}$ with the scan rate of $50 \mathrm{mV} / \mathrm{s}$. Cyclic voltammograms demonstrate redox behavior around $-0.2 \mathrm{~V}$. A sharp peak was observed around $-0.18 \mathrm{~V}$, which is due to the oxidation of $\mathrm{Cu}^{+}$to $\mathrm{Cu}^{2+}$, as reported in the literature. ${ }^{19}$ This is noteworthy that the electrocatalytic oxidation current was observed in $\mathrm{CV}$ beyond the potential of $0.5 \mathrm{~V}$ to OER in $0.5 \mathrm{M}$ $\mathrm{KOH}$ according to the following reaction occurs at anode: $4 \mathrm{OH}^{-} \rightarrow 2 \mathrm{H}_{2} \mathrm{O}+2 \mathrm{O}_{2}+4 \mathrm{e}^{-}$. From the $\mathrm{CV}$ curves, the nanocrystalline $\mathrm{CuGaO}_{2}$ hexagons generate higher current than the sub-micron sized $\mathrm{CuGaO}_{2}$ plates and micron-sized $\mathrm{CuGaO}_{2}$ particles.

Chrono-amperometry (CA) is a potentiostatic true quantitative measurement to investigate the electro-catalytic behavior of the nanomaterials at the fixed potential with time. Figure 5b shows the chrono-amperometric measurements of the nanocrystalline hexagons, sub-micron sized plates and micron-sized particles of $\mathrm{CuGaO}_{2}$ at the fixed potential of $0.60 \mathrm{~V}$ for 250 seconds for OER. By comparing the catalytic activity of all four electrodes with CA, it is clearly observed that the nanocrystalline $\mathrm{CuGaO}_{2}$ hexagons generate higher current than the sub-micron sized plates and micron-sized particles of $\mathrm{CuGaO}_{2}$. It means that the nanocrystalline $\mathrm{CuGaO}_{2}$ hexagons show higher electro-catalytic activity than the sub-micron and micron sized particles toward OER. No current is generated when we use an electrode without any electro-catalyst. The electrode without catalytic materials contains only carbon black and PVDF. A careful visualization shows that the current decreases with time using the sub-micron sized $\mathrm{CuGaO}_{2}$ plates obtained via sono-chemical process as the catalysts while the generated current was more stable with time when the nanocrystalline $\mathrm{CuGaO}_{2}$ hexagons obtained via hydrothermal process were used as the catalysts. This could be possible because of the degradation of the $\mathrm{CuGaO}_{2}$ plates as the catalysts on oxidation. Therefore, the $\mathrm{CuGaO}_{2}$ hexagons are more stable electro-catalytic materials compared to the other two samples.

The current density for the nanocrystalline $\mathrm{CuGaO}_{2}$ hexagons, sub-micron sized plates and micron-sized particles was calculated by using the electro-active surface area of the electrode. The geometric electro-active surface area of electrodes for OER was calculated by using Randles-Sevcik equation ${ }^{28,29,30}$ as that of the nanocrystalline hexagons is equal to $0.21 \mathrm{~cm}^{2}$, that of the sub-micron sized plates to $0.19 \mathrm{~cm}^{2}$, and that of the micron-sized particles to $0.12 \mathrm{~cm}^{2}$. Commonly, the current densities of the materials were calculated using the resulting currents obtained from the electrochemical measurements divided by the geometric electroactive surface 
area of the electrode. Therefore, the current densities of the nanocrystalline $\mathrm{CuGaO}_{2}$ hexagons, sub-micron sized plates and micron-sized particles at $0.60 \mathrm{~V}$ were found to be 26, 23 and 5 $\mathrm{mA} / \mathrm{cm}^{2}$, respectively. So the current density of the nanocrystalline $\mathrm{CuGaO}_{2}$ hexagons was found to be more than 5 times higher than the micron-sized $\mathrm{CuGaO}_{2}$ particles while close to that of the sub-micron sized $\mathrm{CuGaO}_{2}$ plates. To the best of our knowledge, there were very few reports in the literature on delafossite $\mathrm{CuRhO}_{2}, \mathrm{CuGaO}_{2}, \mathrm{CuFeO}_{2}$, and $\mathrm{CuAlO}_{2}$ micron-sized particles as the electro-catalysts for OER using 1.0 M KOH electrolyte and reversible hydrogen electrode as a reference electrode by applying the potential of $1.6 \mathrm{~V} \cdot{ }^{17}$ Moreover, the nanocrystalline delafossite $\mathrm{CuGaO}_{2}$ hexagons are an efficient electro-catalyst to OER at much lower potentials compared to the reported delafossite compounds. ${ }^{17}$ Previously, the current density of $\mathrm{CuGaO}_{2}$ particles for OER was reported to be $\sim 8 \mathrm{~mA} / \mathrm{cm}^{2}$ at the applied potential of $1.6 \mathrm{~V},{ }^{17}$ while our results here showed that nanocrystalline $\mathrm{CuGaO}_{2}$ hexagons and submicron sized plates generate much higher current densities of $\sim 26$ and $\sim 23 \mathrm{~mA} / \mathrm{cm}^{2}$, respectively, at much lower applied potential, i.e. $0.60 \mathrm{~V}$. Table 1 shows the comparison of the electro-catalytic performances of the as-synthesized delafossite $\mathrm{CuGaO}_{2}$ nanostructures with those of previously reported delafossite compounds. These nanocrystalline hexagons and sub-micron sized plates of delafossite $\mathrm{CuGaO}_{2}$ show higher current density than metallic copper nanoparticles $\left(15 \mathrm{~mA} / \mathrm{cm}^{2}\right.$ with Pt as a working electrode), ${ }^{19}$ and copper (I) oxide nanostructures $\left(20 \mathrm{~mA} / \mathrm{cm}^{2}\right.$ with glassy carbon as a working electrode and $35.5 \mathrm{~mA} / \mathrm{cm}^{2}$ with Pt as a working electrode) versus $\mathrm{Ag} / \mathrm{AgCl} .{ }^{19}$ Several other materials like $\mathrm{IrO}_{2}, \mathrm{RhO}_{2}$ are the important electro-catalysts for OER, but it is always prominent to find less expensive catalysts as alternates. The nanocrystalline $\mathrm{CuGaO}_{2}$ hexagons also show much higher electro-catalytic activity than $\operatorname{IrO}_{2}\left(\sim 4 \mu \mathrm{A} / \mathrm{cm}^{2}\right.$ in acidic and $\sim 2 \mu \mathrm{A} / \mathrm{cm}^{2}$ in alkaline medium) and $\mathrm{RuO}_{2}\left(\sim 10 \mu \mathrm{A} / \mathrm{cm}^{2}\right.$ in acidic and $\sim 3 \mu \mathrm{A} / \mathrm{cm}^{2}$ in alkaline medium $)$ at $1.48 \mathrm{~V}$ versus RHE. $^{31}$ The current density of $\mathrm{IrO}_{2}$ nanoflowers was reported to be of $0.5 \mathrm{~mA} / \mathrm{cm}^{2}$ in $0.1 \mathrm{M}$ buffer solution using glassy carbon electrode versus Ag/AgCl. ${ }^{32}$

The current densities of the nanocrystalline $\mathrm{CuGaO}_{2}$ hexagons, sub-micron sized plates and micron-sized particles were also calculated using the amount of materials pasted on electrode, observed current and BET surface area of the materials. The current densities for OER were found to be $0.099,0.062$ and $0.015 \mathrm{~mA} / \mathrm{cm}^{2}$ of nanocrystalline hexagons, sub-micron sized plates and micron-sized particles of $\mathrm{CuGaO}_{2}$, respectively, at $0.60 \mathrm{~V}$. The electro-catalytic performance of nanocrystalline $\mathrm{CuGaO}_{2}$ hexagons for OER was found much higher (1.5 and 6 times) than the 
performances observed with sub-micron sized $\mathrm{CuGaO}_{2}$ plates and micron-sized $\mathrm{CuGaO}_{2}$ particles.

These delafossite $\mathrm{CuGaO}_{2}$ samples have also been used as electro-catalysts for HER. CV curves show that the hydrogen evolution begins from $-0.9 \mathrm{~V}$ versus $\mathrm{Ag} / \mathrm{AgCl}$ electrode according to the following reaction: $2 \mathrm{H}_{2} \mathrm{O}+2 \mathrm{e}^{-} \rightarrow \mathrm{H}_{2}+2 \mathrm{OH}^{-}$(Figure $5 \mathrm{a}$ ). During the electro-catalysis process, electrons transfer from the delafossite $\mathrm{CuGaO}_{2}$ electrode materials to water molecules to generate $\mathrm{H}_{2}$ and $\mathrm{OH}^{-}$. Nanocystalline $\mathrm{CuGaO}_{2}$ hexagons perform better electro-catalytic activity compared to the sub-micron sized $\mathrm{CuGaO}_{2}$ plates and micron-sized particles to HER. CA studies of the delafossite $\mathrm{CuGaO}_{2}$ particles were carried out to confirm the catalytic activity toward the evolution of hydrogen in $0.5 \mathrm{M} \mathrm{KOH}$ at $-1.2 \mathrm{~V}$ for 250 seconds (Figure 5c). By comparing the current density of all three electrode materials from CA, we clearly observe that the nanocrystalline hexagons generate higher current compared to the sub-micron sized plates and the micron-sized particles with time. The current densities of the nanocrystalline hexagons, submicron sized plates and micron-sized particles were found to be about 65,45 , and $35 \mathrm{~mA} / \mathrm{cm}^{2}$, respectively. The current density is directly proportional to the generation of oxygen or hydrogen which depends on both the surface area and the morphology of the catalysts. By using the BET surface area to compare the catalytic activities of all three electrodes, we examined that the nanocrystalline hexagons $\left(0.25 \mathrm{~mA} / \mathrm{cm}^{2}\right)$ show higher efficiency compared to the sub-micron sized plates $\left(0.122 \mathrm{~mA} / \mathrm{cm}^{2}\right)$ and the micron-sized particles $\left(0.105 \mathrm{~mA} / \mathrm{cm}^{2}\right)$. The current density obtained could be a function of both the faradaic and non-faradaic processes. The faradic process is the only one that contributes to either OER or HER by the illustration of charge being transferred with these $\mathrm{CuGaO}_{2}$ particles while the non-faradic process stimulates the formation of the electrical double layer. Note that here we reported that delafossite $\mathrm{CuGaO}_{2}$ is also an efficient electro-catalyst for HER for the first time. The investigation of $\mathrm{CuGaO}_{2}$ electrocatalysts for the generation of hydrogen is highly admirable as the next generation fuel. 

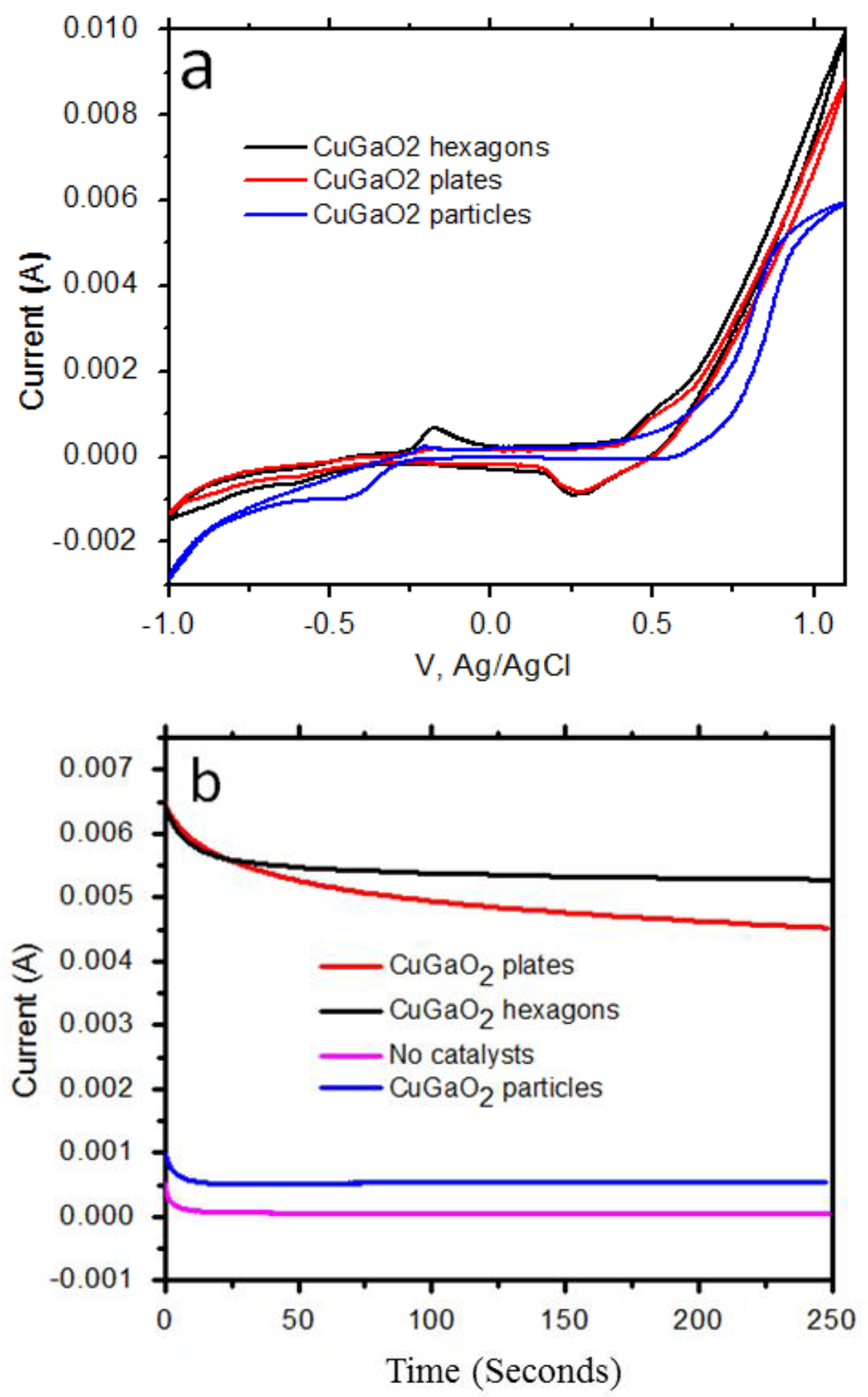


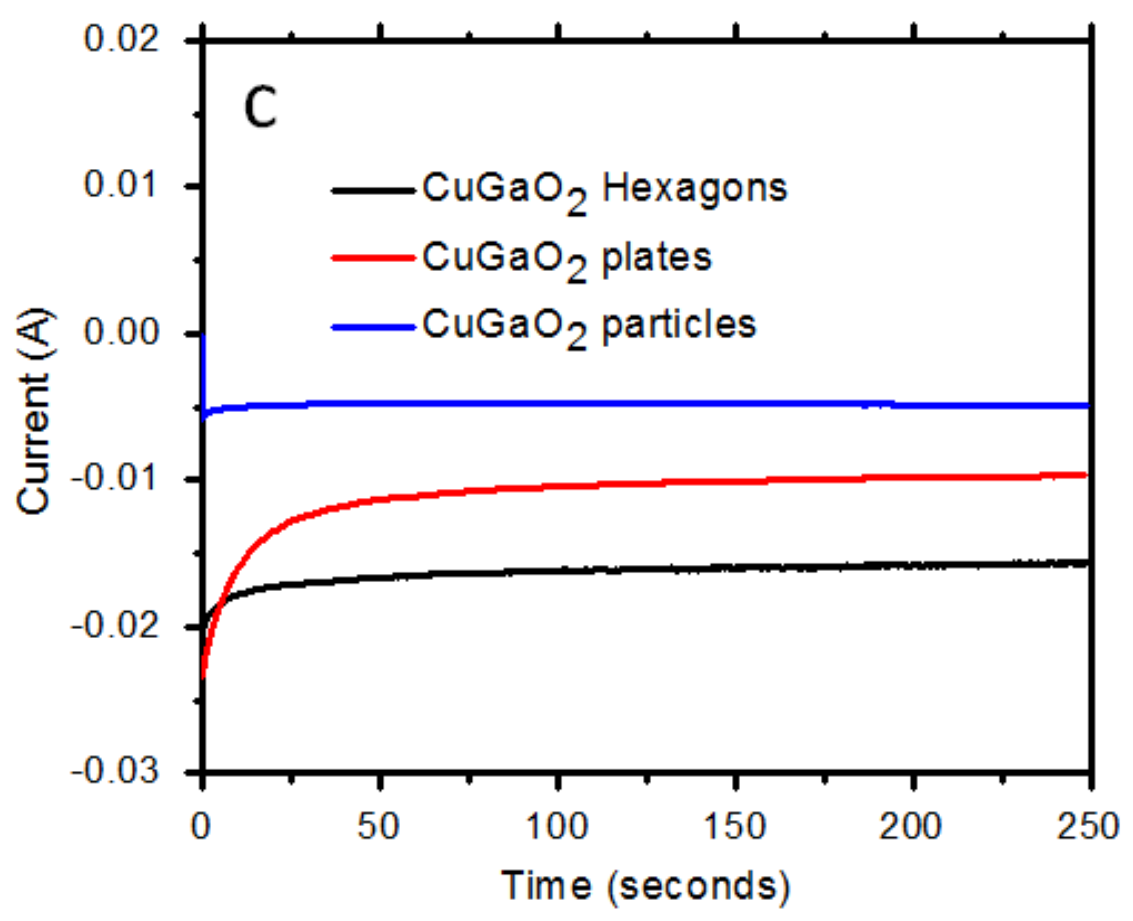

Figure 5. (a) Cyclic voltammograms of the nanocrystalline $\mathrm{CuGaO}_{2}$ hexagons, sub-micron sized $\mathrm{CuGaO}_{2}$ plates and micron-sized $\mathrm{CuGaO}_{2}$ particles in $0.5 \mathrm{M} \mathrm{KOH}$ by applying the potential range from -1.0 to $1.1 \mathrm{~V}$ vs $\mathrm{Ag} / \mathrm{AgCl}$ with scan rate of $50 \mathrm{mV} / \mathrm{s}$; (b) chronoamperometric voltammograms of the nanocrystalline $\mathrm{CuGaO}_{2}$ hexagons, sub-micron sized $\mathrm{CuGaO}_{2}$ plates and micron-sized $\mathrm{CuGaO}_{2}$ particles for OER at $0.6 \mathrm{~V}$ for 250 seconds; (c) Chronoamperometric voltammograms of the nanocrystalline $\mathrm{CuGaO}_{2}$ hexagons, sub-micron sized $\mathrm{CuGaO}_{2}$ plates and micron-sized $\mathrm{CuGaO}_{2}$ particles for $\mathrm{HER}$ at $-1.2 \mathrm{~V}$ for 250 seconds. Note that $\mathrm{N}_{2}$ gas was purged through the electrolyte for 5 minutes prior to the electrochemical measurements to remove dissolved air from the electrolyte.

Table 1. Comparison of the electro-catalytic activities of the as-synthesized delafossite $\mathrm{CuGaO}_{2}$ nanostructures for OER with previous reports in the literature

\begin{tabular}{|l|l|l|l|}
\hline Samples & Applied Potential & Current Density & Ref. \# \\
\hline Nanocrystalline $\mathrm{CuGaO}_{2}$ hexagons & $0.60 \mathrm{~V}$ & $26 \mathrm{~mA} / \mathrm{cm}^{2}$ & Present study \\
\hline $\mathrm{CuGaO}_{2}$ sub-micron sized plates & $0.60 \mathrm{~V}$ & $23 \mathrm{~mA} / \mathrm{cm}^{2}$ & Present study \\
\hline $\mathrm{CuGaO}_{2}$ micron-sized particles & $0.60 \mathrm{~V}$ & $5 \mathrm{~mA} / \mathrm{cm}^{2}$ & Present study \\
\hline $\mathrm{CuGaO}_{2}$ micron-sized particles & $1.6 \mathrm{~V}$ & $6 \mathrm{~mA} / \mathrm{cm}^{2}$ & 17 \\
\hline
\end{tabular}




\begin{tabular}{|c|c|c|c|}
\hline $\mathrm{CuRhO}_{2}$ micron-sized particles & $1.6 \mathrm{~V}$ & $8 \mathrm{~mA} / \mathrm{cm}^{2}$ & 17 \\
\hline $\mathrm{CuGaO}_{2}$ micron-sized particles & $2.0 \mathrm{~V}$ & $30 \mathrm{~mA} / \mathrm{cm}^{2}$ & 17 \\
\hline $\mathrm{CuAlO}_{2}$ micron-sized particles & $2.0 \mathrm{~V}$ & $10 \mathrm{~mA} / \mathrm{cm}^{2}$ & 17 \\
\hline $\mathrm{CuFeO}_{2}$ micron-sized particles & $2.0 \mathrm{~V}$ & $8 \mathrm{~mA} / \mathrm{cm}^{2}$ & 17 \\
\hline $\mathrm{CuYO}_{2}$ micron-sized particles & $2.0 \mathrm{~V}$ & $5 \mathrm{~mA} / \mathrm{cm}^{2}$ & 17 \\
\hline
\end{tabular}

By using the cyclic voltammetry, the freshly prepared electrodes of the nanocrystalline $\mathrm{CuGaO}_{2}$ hexagons (Figure 6a), sub-micron sized $\mathrm{CuGaO}_{2}$ plates (Figure 6b) and micron-sized $\mathrm{CuGaO}_{2}$ particles (Figure 6c) were also used to investigate the OER in $\mathrm{O}_{2}$ saturated $0.5 \mathrm{M} \mathrm{KOH}$ by applying potential ranging from -0.60 to $0.80 \mathrm{~V}$ versus $\mathrm{Ag} / \mathrm{AgCl}$ electrode. All the measurements were carried out at various scan rates of $10,25,50 \mathrm{mV} / \mathrm{s}$. These delafossite $\mathrm{CuGaO}_{2}$ samples start the current generation from $0.55 \mathrm{~V}$ and act as electro-catalysts for OER beyond this potential. From the CV curves, we observed that the peak current is higher for the nanocrystalline hexagons than the sub-micron sized plates and micron-sized particles at $0.8 \mathrm{~V}$ versus $\mathrm{Ag} / \mathrm{AgCl}$ (Figure 6a, 6b and 6c). The peak current is directly proportional to the amount of oxygen evolved during the electrolysis which depends on the surface area and morphology of the electro-catalysts.

The electro-catalytic activities of these nanocrystalline hexagons, sub-micron sized plates and micron-sized particles of delafossite $\mathrm{CuGaO}_{2}$ were also investigated by chrono-amperometric measurements in $\mathrm{O}_{2}$ saturated $0.5 \mathrm{M} \mathrm{KOH}$ at $0.60 \mathrm{~V}$ for 200 seconds (Figure 6d). In the chronoamperometric experiments, the chemical reaction occurred on the surface of working electrode to generate the current during the electrolysis at the applied voltage of $0.60 \mathrm{~V}$ versus $\mathrm{Ag} / \mathrm{AgCl}$ and the electrochemical reaction stops when the potential is switched off and hence current drops to zero. Calculated by using the Randles-Sevcik equation, the geometric electro-active surface area of the electrodes was found to be $0.09,0.126$ and $0.085 \mathrm{~cm}^{2}$ of the nanocrystalline $\mathrm{CuGaO}_{2}$ hexagons, sub-micron sized $\mathrm{CuGaO}_{2}$ plates and micron-sized $\mathrm{CuGaO}_{2}$ particles, respectively. ${ }^{28,29,30}$ By comparing the electro-catalytic activity of the nanocrystalline $\mathrm{CuGaO}_{2}$ hexagons, sub-micron sized plates, and micron-sized particles for OER, it was clearly observed again that the nanocrystalline hexagons $\left(20 \mathrm{~mA} / \mathrm{cm}^{2}\right)$ possess better catalytic activity than the sub-micron sized plates $\left(12 \mathrm{~mA} / \mathrm{cm}^{2}\right)$ and micron-sized particles $\left(5 \mathrm{~mA} / \mathrm{cm}^{2}\right)$ at $0.6 \mathrm{~V}$ versus $\mathrm{Ag} / \mathrm{AgCl}$. Recently, Stoerzinger et al. have reported the orientation dependent oxygen evolution 
activity of $\mathrm{IrO}_{2}$ nanocrystals $\left(3 \mu \mathrm{A} / \mathrm{cm}^{2}\right.$ for $<100>$ and $0.5 \mu \mathrm{A} / \mathrm{cm}^{2}$ for $<110>$ ) in $\mathrm{O}_{2}$-saturated $0.1 \mathrm{M} \mathrm{KOH}$ at $1.2 \mathrm{~V}$ versus RHE. ${ }^{33}$ Hence, the nanocrystalline $\mathrm{CuGaO}_{2}$ hexagons show enhanced electro-catalytic behavior than the most active $\mathrm{IrO}_{2}$ electrode materials in oxygen saturated electrolyte at $0.6 \mathrm{~V}$ versus $\mathrm{Ag} / \mathrm{AgCl}$. For OER, the current densities were also calculated using the BET surface area. The current densities were found to be $0.033,0.021$ and 0.011 of the nanocrystalline $\mathrm{CuGaO}_{2}$ hexagons, sub-micron sized $\mathrm{CuGaO}_{2}$ plates and micronsized $\mathrm{CuGaO}_{2}$ particles, respectively. Therefore, oxygen evolution efficiency of the nanocrystalline $\mathrm{CuGaO}_{2}$ hexagons is much better than the sub-micron sized $\mathrm{CuGaO}_{2}$ plates and micron-sized $\mathrm{CuGaO}_{2}$ particles. The observed current is proportional to the amount of oxygen or hydrogen generated during the electrolysis of water. The amount of current generation is a function of surface area, size and morphology of nanomaterials. The specific surface area (from $\mathrm{BET})$ of the nanocrystalline $\mathrm{CuGaO}_{2}$ hexagons was found to be higher $\left(2.63 \mathrm{~m}^{2} / \mathrm{g}\right)$ compared to the sub-micron sized $\mathrm{CuGaO}_{2}$ plates $\left(2.33 \mathrm{~m}^{2} / \mathrm{g}\right)$ and micron-sized $\mathrm{CuGaO}_{2}$ particles $\left(0.42 \mathrm{~m}^{2} / \mathrm{g}\right)$, which also support the observed electrolysis of water to OER and HER. 

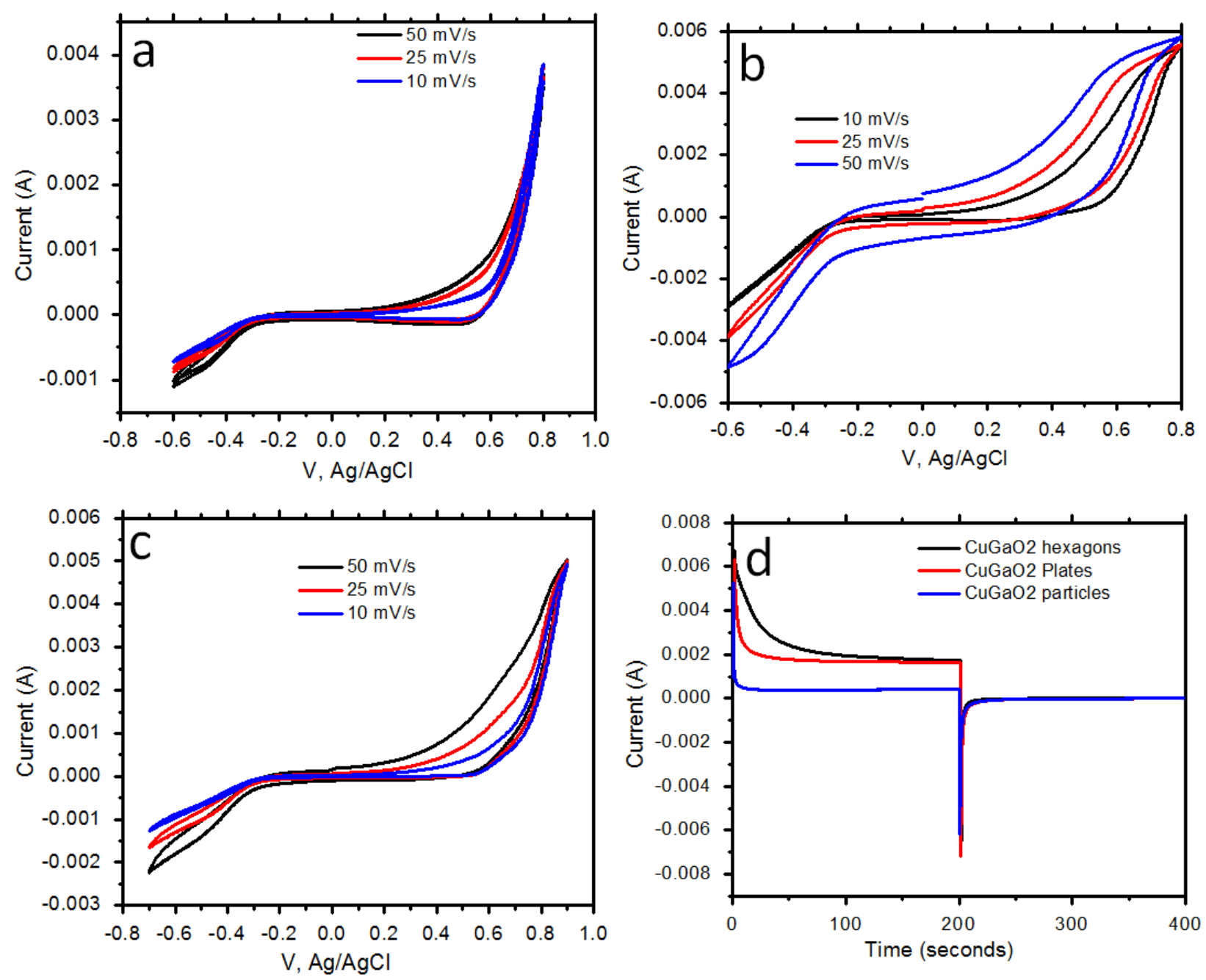

Figure 6. Cyclic voltammograms of the (a) nanocrystalline $\mathrm{CuGaO}_{2}$ hexagons; (b) sub-micron sized $\mathrm{CuGaO}_{2}$ plates; (c) micron-sized $\mathrm{CuGaO}_{2}$ particles for OER in saturated $\mathrm{O}_{2}$ and $0.5 \mathrm{M}$ $\mathrm{KOH}$ using various scan rates, i.e. 10, 25, and $50 \mathrm{mV} / \mathrm{s}$;. (d) Chronoamperometric voltammograms of the nanocrystalline $\mathrm{CuGaO}_{2}$ hexagons, sub-micron sized $\mathrm{CuGaO}_{2}$ plates and micron-sized $\mathrm{CuGaO}_{2}$ particles for OER in saturated $\mathrm{O}_{2}$ and $0.5 \mathrm{M} \mathrm{KOH}$.

\section{Conclusions}

In the present study, we tested and compared a type of active and cost effective electrode material, i.e. delafossite $\mathrm{CuGaO}_{2}$ with three different morphologies, for the electrolysis of water to sustain the efficiency in fuel generation technology. The phase purity and morphology of the synthesized materials were confirmed from the PXRD, Raman spectroscopy, and electron microscopic studies. The nanocrystalline $\mathrm{CuGaO}_{2}$ hexagons 
show superior electro-catalytic activity than the sub-micron sized plates and micron sized particles of $\mathrm{CuGaO}_{2}$ toward oxygen and hydrogen evolution reactions in both nitrogenand oxygen-saturated $0.5 \mathrm{M} \mathrm{KOH}$ electrolyte versus $\mathrm{Ag} / \mathrm{AgCl}$. Therefore, it is expected that these delafossite $\mathrm{CuGaO}_{2}$ particles could be useful for sustainable energy conversion applications.

\section{Acknowledgements}

The authors thank the support from the American Chemical Society - Petroleum Research Fund \#51497, the Air Force Office of Scientific Research (award \# FA9550-121-0159), and the National Science Foundation under DMR grant \# 0934157 (PREMUTPA/UMN-Science and Engineering of Polymeric and Nanoparticle-based Materials for Electronic and Structural Applications). J.A. is gratefully acknowledged "The Deanship of Scientific Research, Research Center, College of Science, King Saud University, Kingdom of Saudi Arabia. The authors also thank Mr. Q. Li for taking SEM images, Ms. T. Olmedo for taking TEM images, Dr. M. Pokhrel for EDX studies, and Ms. J. Cruz for performing BET measurements.

\section{References}

1 Srinivasan, R.; Chavillon, B.; Doussier-Brochard, C.; Cario, L.; Paris, M.; Gautron, E.; Deniard, P.; Odobel, F.; Jobic, S., Tuning the size and color of the $p$-type wide band gap delafossite semiconductor $\mathrm{CuGaO}_{2}$ with ethylene glycol assisted hydrothermal synthesis. Journal of Materials Chemistry 2008, 18 (46), 5647-5653.

2 Yu, M.; Natu, G.; Ji, Z.; Wu, Y., p-type dye-sensitized solar cells based on delafossite $\mathrm{CuGaO}_{2}$ nanoplates with saturation photovoltages exceeding $460 \mathrm{mV}$. The Journal of Physical Chemistry Letters 2012, 3 (9), 1074-1078.

3 Xu, Z.; Xiong, D.; Wang, H.; Zhang, W.; Zeng, X.; Ming, L.; Chen, W.; Xu, X.; Cui, J.; Wang, M.; Powar, S.; Bach, U.; Cheng, Y.-B., Remarkable photocurrent of $p$-type dyesensitized solar cell achieved by size controlled $\mathrm{CuGaO}_{2}$ nanoplates. Journal of Materials Chemistry A 2014, 2 (9), 2968-2976. 
4 Li, J.; Sleight, A. W.; Jones, C. Y.; Toby, B. H., Trends in negative thermal expansion behavior for $\mathrm{AMO}_{2}(\mathrm{~A}=\mathrm{Cu}$ or $\mathrm{Ag} ; \mathrm{M}=\mathrm{Al}$, Sc, In, or La $)$ compounds with the delafossite structure. Journal of Solid State Chemistry 2005, 178 (1), 285-294.

5 John, M.; Heuss-Aßbichler, S.; Park, S.; Ullrich, A.; Benka, G.; Petersen, N.; Rettenwander, D.; Horn, S. R., Low-temperature synthesis of $\mathrm{CuFeO}_{2}$ (delafossite) at $70^{\circ} \mathrm{C}$ : A new process solely by precipitation and ageing. Journal of Solid State Chemistry 2016, 233, 390-396.

6 Nie, X.; Wei, S.-H.; Zhang, S. B., Bipolar doping and band-gap anomalies in delafossite transparent conductive oxides. Physical Review Letters 2002, 88 (6), 066405.

7 Robertson, J.; Peacock, P. W.; Towler, M. D.; Needs, R., Electronic structure of $p$-type conducting transparent oxides. Thin Solid Films 2002, 411 (1), 96-100.

8 Kawazoe, H.; Yasukawa, M.; Hyodo, H.; Kurita, M.; Yanagi, H.; Hosono, H., P-type electrical conduction in transparent thin films of $\mathrm{CuAlO}_{2}$. Nature 1997, 389 (6654), 939942.

9 Han, M.J.; Huang, T.; Zhang, J.Z.; Li, Y.W.; Hu, .G., Structural, optical and electrical properties of delafossite $\mathrm{CuGaO}_{2}$ films grown by sol-gel method. Proceedings of SPIE 2013, 906809. doi:10.1117/12.2053125.

10 Omata, T.; Nagatani, H.; Suzuki, I.; Kita, M.; Yanagi, H.; Ohashi, N., Wurtzite $\mathrm{CuGaO}_{2}$ : a new direct and narrow band gap oxide semiconductor applicable as a solar cell absorber. Journal of the American Chemical Society 2014, 136 (9), 3378-3381.

11 Renaud, A.; Chavillon, B.; Le Pleux, L.; Pellegrin, Y.; Blart, E.; Boujtita, M.; Pauporte, T.; Cario, L.; Jobic, S.; Odobel, F., $\mathrm{CuGaO}_{2}$ : a promising alternative for $\mathrm{NiO}$ in $p$-type dye solar cells. Journal of Materials Chemistry 2012, 22 (29), 14353-14356.

12 Gurunathan, K.; Baeg, J.-O.; Lee, S. M.; Subramanian, E.; Moon, S.-J.; Kong, K.-J., Visible light assisted highly efficient hydrogen production from $\mathrm{H}_{2} \mathrm{~S}$ decomposition by $\mathrm{CuGaO}_{2}$ and $\mathrm{CuGa}_{1-\mathrm{x}} \mathrm{In}_{\mathrm{x}} \mathrm{O}_{2}$ delafossite oxides bearing nanostructured co-catalysts. Catalysis Communications 2008, 9 (3), 395-402.

13 Lekse, J. W.; Underwood, M. K.; Lewis, J. P.; Matranga, C., Synthesis, characterization, electronic structure, and photocatalytic behavior of $\mathrm{CuGaO}_{2}$ and $\mathrm{CuGa}_{1-\mathrm{x}} \mathrm{Fe}_{\mathrm{x}} \mathrm{O}_{2}(\mathrm{x}=0.05$, 0.10, 0.15, 0.20) delafossites. The Journal of Physical Chemistry C 2011, 116 (2), 18651872. 
14 Herraiz-Cardona, I.; Fabregat-Santiago, F.; Renaud, A.; Julián-López, B.; Odobel, F.; Cario, L.; Jobic, S.; Giménez, S., Hole conductivity and acceptor density of p-type $\mathrm{CuGaO}_{2}$ nanoparticles determined by impedance spectroscopy: The effect of $\mathrm{Mg}$ doping. Electrochimica Acta 2013, 113, 570-574.

15 Carcia, P. F.; Shannon, R. D.; Bierstedt, P. E.; Flippen, R. B., 2 electrocatalysis on thin film metallic oxide electrodes with the delafossite structure. Journal of the Electrochemical Society 1980, 127 (9), 1974-1978.

16 Hinogami, R.; Toyoda, K.; Aizawa, M.; Kawasaki, T.; Gyoten, H., Copper delafossite anode for water electrolysis. ECS Transactions 2013, 58 (2), 27-31.

17 Hinogami, R.; Toyoda, K.; Aizawa, M.; Yoshii, S.; Kawasaki, T.; Gyoten, H., Active copper delafossite anode for oxygen evolution reaction. Electrochemistry Communications 2013, 35, 142-145.

18 Ahmed, J., Mao, Y., Delafossite $\mathrm{CuAlO}_{2}$ nanoparticles with electrocatalytic activity toward oxygen and hydrogen evolution reactions, in Nanomaterials for Sustainable Energy, ed. Jingbo Louise Liu and Sajid Bashir, American Chemical Society, Washington DC, 2015, Chpater 4, 57-72.

19 Kumar, B.; Saha, S.; Ganguly, A.; Ganguli, A. K., A facile low temperature $\left(350^{\circ} \mathrm{C}\right)$ synthesis of $\mathrm{Cu}_{2} \mathrm{O}$ nanoparticles and their electrocatalytic and photocatalytic properties. RSC Advances 2014, 4 (23), 12043-12049.

20 Ahmed, J.; Trinh, P.; Mugweru, A. M.; Ganguli, A. K., Self-assembly of copper nanoparticles (cubes, rods and spherical nanostructures): Significant role of morphology on hydrogen and oxygen evolution efficiencies. Solid State Sciences 2011, 13 (5), 855861.

21 Ahmed, J.; Ganguly, A.; Saha, S.; Gupta, G.; Trinh, P.; Mugweru, A. M.; Lofland, S. E.; Ramanujachary, K. V.; Ganguli, A. K., Enhanced electrocatalytic activity of coppercobalt nanostructures. The Journal of Physical Chemistry C 2011, 115 (30), 1452614533.

22 Melnikov, P.; Nascimento, V. A.; Zanoni Consolo, L. Z., Thermal decomposition of gallium nitrate hydrate and modeling of thermolysis products. Journal of Thermal Analysis and Calorimetry 2012, 107 (3), 1117-1121. 
23 Kumekawa, Y.; Hirai, M.; Kobayashi, Y.; Endoh, S.; Oikawa, E.; Hashimoto, T., Evaluation of thermodynamic and kinetic stability of $\mathrm{CuAlO}_{2}$ and $\mathrm{CuGaO}_{2}$. Journal of Thermal Analysis and Calorimetry 2010, 99 (1), 57-63.

24 Amrute, A. P.; Łodziana, Z.; Mondelli, C.; Krumeich, F.; Pérez-Ramírez, J., Solid-state chemistry of cuprous delafossites: synthesis and stability aspects. Chemistry of Materials 2013, 25 (21), 4423-4435.

25 Han, M.; Jiang, K.; Zhang, J.; Yu, W.; Li, Y.; Hu, Z.; Chu, J., Structural, electronic band transition and optoelectronic properties of delafossite $\mathrm{CuGa}_{1-\mathrm{x}} \mathrm{Cr}_{\mathrm{x}} \mathrm{O}_{2}(0 \leq \mathrm{x} \leq 1)$ solid solution films grown by the sol-gel method. Journal of Materials Chemistry 2012, 22 (35), 18463-18470.

26 Pellicer-Porres, J.; Segura, A.; Martínez, E.; Saitta, A. M.; Polian, A.; Chervin, J. C.; Canny, B., Vibrational properties of delafossite $\mathrm{CuGaO}_{2}$ at ambient and high pressures. Physical Review B 2005, 72 (6), 064301.

27 Ahmed, J.; Menaka; Ganguli, A. K., Controlled growth of nanocrystalline rods, hexagonal plates and spherical particles of the vaterite form of calcium carbonate. CrystEngComm 2009, 11 (5), 927-932.

28 Taurino, I.; Carrara, S.; Giorcelli, M.; Tagliaferro, A.; De Micheli, G., Comparison of two different carbon nanotube-based surfaces with respect to potassium ferricyanide electrochemistry. Surface Science 2012, 606 (3-4), 156-160.

29 Min-Jung, S.; Dong-Hwa, Y.; Joon-Hyung, J.; Nam-Ki, M.; Suk-In, H., Comparison of effective working electrode aAreas on planar and porous silicon substrates for cholesterol biosensor. Japanese Journal of Applied Physics 2006, 45 (9R), 7197.

30 Aljabali, A. A. A.; Barclay, J. E.; Butt, J. N.; Lomonossoff, G. P.; Evans, D. J., Redoxactive ferrocene-modified Cowpea mosaic virus nanoparticles. Dalton Transactions 2010, 39 (32), 7569-7574.

31 Lee, Y.; Suntivich, J.; May, K. J.; Perry, E. E.; Shao-Horn, Y., Synthesis and activities of rutile $\mathrm{IrO}_{2}$ and $\mathrm{RuO}_{2}$ nanoparticles for oxygen evolution in acid and alkaline solutions. The Journal of Physical Chemistry Letters 2012, 3 (3), 399-404.

32 Zhao, C.; E, Y.; Fan, L., Enhanced electrochemical evolution of oxygen by using nanoflowers made from a gold and iridium oxide composite. Microchimica Acta 2012, 178 (1-2), 107-114. 
33 Stoerzinger, K. A.; Qiao, L.; Biegalski, M. D.; Shao-Horn, Y., Orientation-dependent oxygen evolution activities of rutile $\mathrm{IrO}_{2}$ and $\mathrm{RuO}_{2}$. The Journal of Physical Chemistry Letters 2014, 5 (10), 1636-1641. 